\title{
Development of Meta-Representations: Procedural Metacognition and the Relationship to Theory of Mind
}

\author{
Emanuel Feurer ${ }^{1}$, Raluca Sassu ${ }^{2}$, Patricia Cimeli ${ }^{1} \&$ Claudia M. Roebers ${ }^{1}$ \\ ${ }^{1}$ Center for Cognition, Learning and Memory, University of Bern, Bern, Switzerland \\ ${ }^{2}$ Department of Journalism, Public Relations, Sociology and Psychology, "Lucian Blaga" University of Sibiu, \\ Sibiu, Romania \\ Correspondence: Emanuel Feurer, University of Bern, Center for Cognition, Learning and Memory, Fabrikstrasse \\ 8, 3012 Bern, Switzerland. Tel: 41-031-631-4725. E-mail: emanuel.feurer@psy.unibe.ch
}

Received: October 14, 2014

Accepted: December 16, 2014

Online Published: March 25, 2015

doi:10.5539/jedp.v5n1p6

URL: http://dx.doi.org/10.5539/jedp.v5n1p6

\begin{abstract}
In several studies it was shown that metacognitive ability is crucial for children and their success in school. Much less is known about the emergence of that ability and its relationship to other meta-representations like Theory of Mind competencies. In the past years, a growing literature has suggested that metacognition and Theory of Mind could theoretically be assumed to belong to the same developmental concept. Since then only a few studies showed empirically evidence that metacognition and Theory of Mind are related. But these studies focused on declarative metacognitive knowledge rather than on procedural metacognitive monitoring like in the present study: $N=159$ children were first tested shortly before making the transition to school (aged between 5 $1 / 2$ and $7 \frac{1}{2}$ years) and one year later at the end of their first grade. Analyses suggest that there is in fact a significant relation between early metacognitive monitoring skills (procedural metacognition) and later Theory of Mind competencies. Notably, language seems to play a crucial role in this relationship. Thus our results bring new insights in the research field of the development of meta-representation and support the view that metacognition and Theory of Mind are indeed interrelated, but the precise mechanisms yet remain unclear.
\end{abstract}

Keywords: children, cognitive development, language, meta-representation, procedural metacognition, theory of mind

\section{Introduction}

Almost everybody has some memories about the first day in kindergarten or school and this transition from home to a new environment entails many new demands and challenges for children. In this context and under the label of "children's school readiness", self-regulatory processes including executive functions (Blair \& Razza, 2007), attentional skills (Duncan et al., 2007), but also precursors of academic skills (i.e. phonological awareness, Anthony, Williams, McDonald, \& Francis, 2007) have attracted intensive research interest. Surprisingly, two other aspects of cognitive development have largely been overlooked in these lines of research, most likely because they are not considered as a typical indicator for "school readiness". One of them is metacognition, which is widely known as being crucial for successful learning and involves skills such as detecting and correcting mistakes while performing a task (Roebers, Krebs, \& Roderer, 2014). Another one is Theory of Mind, which is important for successful social interactions (Caputi, Lecce, Pagnin, \& Banerjee, 2012; Jenkins \& Astington, 2000) and inferring teachers' intentions in classroom discourse (Astington \& Pelletier, 1996; Davis-Unger \& Carlson, 2008). These two psychological constructs both reflect an individual's ability to build meta-representations (about oneself and others). The present study aims to bring them together in children in transition from kindergarten to school.

\subsection{Metacognition}

The term metacognition covers factual knowledge about cognition (declarative metacognition; e.g., strategy knowledge) and aspects of regulation of ongoing cognition (procedural metacognition) (Schneider \& Lockl, 2008). The latter can be divided into monitoring and control processes (Nelson \& Narens, 1990): monitoring is the ability to judge one's ongoing cognitive performance, such as estimating the correctness of a response just 
given, and control is based on this subjective monitoring, such as correcting the response just given. From a developmental perspective, it has been noted that children show adequate monitoring skills earlier than corresponding control skills (for a review see Schneider \& Lockl, 2008). Because relatively little research has been done on procedural metacognitive abilities as compared to factual metacognitive knowledge, and because monitoring is the basis for self-regulated learning activities which are considered to be central for children's school readiness (Blair \& Diamond, 2008), the focus of the present study is placed on children's procedural metacognitive monitoring skills.

Monitoring processes can be described as "what the person is aware of and what she or he is feeling when coming across a task processing the information related to it" (Efklides, 2008, p. 279). Monitoring processes mirror meta-representation about actual learning or performance and inform individuals about their learning process or outcome. Classical measures of monitoring are judgments of learning (JOL), used in self-paced learning paradigms (Lockl \& Schneider, 2003), and confidence judgments (CJ) for monitoring performance retrospectively (Pressley, Levin, Ghatala, \& Ahmad, 1987). For self-regulated learning, CJ are assumed to be essential (Kleitman \& Moscrop, 2010), and they have been shown to be a more sensitive indicator of early metacognitive monitoring skills than JOL (Roebers, von der Linden, Schneider, \& Howie, 2007). The present paper will therefore focus on young children's CJ as indicator of their monitoring skills.

Early signs of developing monitoring skills can be observed at 3.5 years of age although they appear to be relatively undifferentiated and seem to rely first on an implicit mechanism rather than on a well-differentiated explicit system, i.e. meta-representations, at older ages (Balcomb \& Gerken, 2008). Similarly, Flavell (2003) suggested different levels of metacognitive monitoring awareness ranging from unconscious uncertainty-certainty responses to fully self-aware uncertainty-certainty responses. These self-aware monitoring skills then gradually improve with age, and by the age of 5 years, children are able to reliably distinguish between what they know and what they don't know (Lyons \& Ghetti, 2011). Though, significant improvements on relative accuracy in monitoring - that is the degree to which a child's monitoring judgments differentially and reliably mirror more subtle differences of certainty and uncertainty (Dunlosky \& Meltcafe, 2009) - are typically observed in the age range of 6 to 8 years (Pressley et al., 1987; Roebers \& Howie, 2003). By the age of 8 to 10 years, this metacognitive discrimination ability, i.e. their ability to differentially use the uncertainty-certainty continuum slowly reaches an adult level (Roebers, 2002; Roebers et al., 2007).

With respect to the specific focus of the present study, it is important to note that independent of participants' age or of the specific aspect of monitoring these skills may capture an individual's ability to form meta-representations about oneself, in the context of metacognition, about one's performance in general or in a given task. Next, we will look at Theory of Mind, thus, at meta-representations about desires, beliefs, or mental states of oneself as well as others.

\subsection{Theory of Mind}

Wimmer and Perner (1983) were the first to raise the question of whether children can form and use meta-representations about other people's desires, beliefs, or state of knowledge, that is, if children have a so-called "Theory of Mind" (ToM). ToM is often described as a folk psychology - a naïve theory about how mental states influence human behavior and thinking, which serves to understand and predict what people think and why they act in a specific way (Astington \& Hughes, 2013; Happé, 2003; Sodian, Perst, \& Meinhardt, 2012). In an everyday example, such understanding could serve as an explanation why someone carries an umbrella: because the person believes that it will rain and wants to stay dry (Happé, 2003). Such an inference requires the understanding that people (including oneself) represent the world mentally and that this mental representation does not need to correspond to reality for example because "it isn't raining the whole day" (Lockl \& Schneider, 2007; Schneider, 2010). To test ToM competencies, research therefore often focuses on children's growing understanding of false belief and also addresses the question how a false belief can guide/mislead and explain subsequent behavior.

With the now classical task of "Maxi and the chocolate", so called first-order false belief understanding can be measured and first signs are typically present at the age of 4 years (Wimmer \& Perner, 1983). So called second-order false belief understanding involves one more representational level (e.g., the child thinks about what his mother thinks his father knows) and emerges later, around the age of six years (Astington \& Hughes, 2013). Although it appears that ToM development follows a relatively well-described general development, there are pronounced individual differences (i.e., for understanding for lies vs. sarcasm), and development continues into the school years (O’Hare, Bremner, Nash, Happé, \& Pettigrew, 2009). 
Of special interest for our research question is the finding of a meta-analysis (Wellman, Cross, \& Watson, 2001) that ascribing and understanding a false belief to oneself or to another person is about equally difficult for children. In fact, Happé (2003) assumed that the same cognitive mechanisms are involved whether a mental state is ascribed to oneself or to others. From this theoretical perspective, one might expect to find substantial relations between ToM and metacognitive monitoring skills, as both concern children's ability to form and operate on meta-representations about mental states, which will be considered next.

\subsection{Linking Procedural Metacognition and Theory of Mind}

On a conceptual level, a number of researchers have proposed a common mechanism behind ToM and metacognitive development (Kuhn, 2000; Wellmann, 1990). In addition, Schneider and Lockl (2008) proposed in their taxonomy of metacognitive components that the umbrella term metacognition (knowledge about cognition) embraces different meta-aspects of human cognition, such as knowledge about the mental world (i.e. ToM), as well as knowledge about memory (i.e. declarative and procedural memory). This theoretical view is indirectly supported by findings showing that 4-year-olds begin to understand that only a person who has knowledge of a fact can later remember or forget that fact (Lyon \& Flavell, 1994). This suggests that these children have acquired knowledge about the mental world and about memory as well. Furthermore, there is evidence for parallel developmental trajectories of children's performance in mindreading tasks and matched metacognitive tasks (Carruthers, 2009).

Direct empirical evidence linking metacognition and ToM is very limited—possibly for two reasons (Misailidi, 2010; Schneider, 2010, 2015): First, early research in these two domains included different age groups making firm comparisons generally difficult to draw. The different methodologies further complicated research on potential mutual links. Whereas ToM research focused on younger children (and the role of emerging ToM skills for social interactions), metacognition research focused on older children (and the role of metacognitive abilities for academic outcomes). Second, research also differs regarding the conceptualization of mental states. That is, ToM research investigates the knowledge about the existence of different mental states, whereas metacognition research focuses on task-relevant processes in the context of performance concerning learning and memory processes. Nevertheless, there is one study by Lockl and Schneider (2007) focusing on the relationship between ToM and declarative metacognitive knowledge, rather than on procedural metacognitive monitoring as we did. It is difficult to infer from these findings a prediction concerning the relationship between procedural metacognitive and ToM, because there is a developmental dissociation between declarative and procedural metacognition and the relation between declarative and procedural metacognition is generally far from perfect (Schneider, 2015). Nevertheless, in their longitudinal study children performed several ToM tasks at their ages of 3, 4, and 5 years. In addition, when they were 5 years old, a metamemory interview was conducted to assess declarative metacognition. Results showed that declarative metacognition and ToM were strongly related, and the correlation remained significant even when language ability was controlled for. In addition, hierarchical regression analyses revealed that, independent of language ability, ToM at age 3 explained a significant amount of the variance in declarative metacognition at 5 years of age. A similar result was found by Lecce, Caputi and Pagnin (2014) who showed that false belief understanding at age 5 predicted children`s understanding of learning processes (a more sophisticated aspect of declarative metacognitive knowledge) at age 8. Overall, these findings lead to the interpretation that ToM might be a precursor of metacognition, in more general terms.

In summary, although there are few attempts to link ToM and metacognition on a conceptual level, only studies from Lockl and Schneider (2007) and Lecce et al. (2014) providing empirical evidence that the development of ToM and metacognition is indeed interrelated. However, as these studies focused on declarative metacognitive knowledge, the question about the relation between procedural metacognition (monitoring) and ToM is still unanswered. Some authors have argued, based on findings concerning relatively good uncertainty monitoring skills in non-human primates (Call, 2010; Beran, Smith, \& Perdue, 2013; Washburn, Gulledge, Beran, \& Smith, 2010); as well as in infants and toddlers (Balcomb \& Gerken, 2008), that for monitoring, no meta-representation of one's performance in the task at hand is necessary. In other words, it has been argued that procedural metacognition may only rely on perceptual inputs and an ambiguity thereof rather than requiring the ability to reflect on one's certainty or uncertainty (Lyons \& Ghetti, 2010, 2013).

\subsection{Study Aims}

Against the background of these contradicting theoretical accounts, the present study aimed to provide more empirical insights into the relation between metacognitive monitoring skills and ToM competencies in children during their transition from kindergarten to school. We expected to find a substantial amount of shared variance 
between metacognitive monitoring and ToM, as both concern an individual's ability to form (and operate on) meta-representations of mental states (certainty/uncertainty, false or true beliefs), and both can be verbally reported. At the same time, young children uncertainty monitoring may still be qualitatively different from older children in terms of the self-awareness (Flavell, 2003). Therefore, we did not expect the link between metacognitive monitoring and ToM to be too close. We targeted this research question through a quantity-oriented, individual differences approach, using correlational and regression analyses.

\section{Method}

\subsection{Participants}

At time 1 the sample included 159 children ( 88 boys) from various Kindergartens in urban and rural areas in Switzerland. The children were tested shortly before entering school at the end of Kindergarten, the mean age was $M=6.1$ years ( $S D=.37$ years). One year later, at time 2 , the children were tested again at the end of their first grade $(M=11.35$ months, $S D=.77)$. Although the language background of $29.6 \%$ of the children was different from Swiss-German, a proportion that is representative for the population in Switzerland, all children were sufficiently fluent in the local language. Children came from various family backgrounds, ranging from lower to upper middle class families; parents' report of their socio-economic status $(86 \%$ return rate) was representative of the Swiss population. All children had written parental consent to participate. After excluding children whose data set was not complete, the final sample consisted of $N=111$ participants (4 children were missing at time 2, 4 children ToM data at time 1 were missing, and 40 children were excluded because no monitoring discrimination score could be computed due to insufficient variance in performance at one or both measure times).

\subsection{Procedure}

The ethical approval for the present study was obtained from the applicable Institutional Review Board. The test setting was similar for both measure times: The children were tested individually in a quiet room at their institution by a trained investigator. Each child participated in two sessions of approximately $40 \mathrm{~min}$, with an average of 10 days between sessions. In the two sessions, a set of task was presented that tapped different cognitive or social-emotional abilities. The order of the tasks was counterbalanced. Before starting each session, children gave verbal consent to participate, and after the second session they received a small gift.

\subsection{Measures}

\subsubsection{Procedural Metacognitive Ability}

Procedural metacognitive ability was assessed at time 1 and 2 with the same paired-associate learning task adopted from Roderer and Roebers (2010, 2014). In this task, children first learned Japanese symbols (Kanji), and after a subsequent recall task, they were asked how confident they were regarding the correctness of each of their answers. The task consisted of two sequenced sets in the same order, each containing 8 different Kanji/picture associations. Before the first set started, a smiley scale (adopted from Jäger, 2004) was introduced to the children, with five different smileys that were verbally labeled as very unsure, unsure, neither unsure nor sure, sure, very sure. Underneath the five smileys was a horizontal arrow with a tip on both sides; it was explained to the participants that this arrow indicates that they can feel anything between very unsure and very sure. To make sure the children understood and were confided with the smiley scale, the introduction included a short story about a child who had to guess several times in which box a ball was hidden - all children showed good understanding of the varying degrees of confidence in the introductory story and use of the smiley scale. After the introduction, children were given the opportunity to practice learning, recognition, and using the smiley scale in a practice trial.

Based on results from previous studies and intensive piloting and to ensure sufficient recall later on, the first set started with two (repeated) learning trials for the same eight Kanji. In each trial, a Kanji/picture pair was presented for 4 seconds preceded by a fixation cross (i.e., a star) that was shown in the center of the screen for 1 second. After the learning trials and a small break, a recognition test followed. For every Kanji, children saw four pictures, and were asked to name and point on the picture they thought corresponded correctly with the target Kanji. Children were allowed to take as long as they needed to select an answer.

After recognition, children's so called "relative accuracy in monitoring" (in terms of item based CJ) was assessed. A Kanji with the four picture alternatives was presented again on the same slide, but this time children were asked to report how sure they were they had chosen the correct picture by pointing on the corresponding smiley on the scale. After another short break, the second set with 8 new Kanji was presented - the order of the 
two sets was counterbalanced between participants and the presented Kanji were randomized in every set. The children did not get any feedback about the correctness of their responses during the whole task.

For relative monitoring in accuracy (item based confidence judgments), also called "calibration" in the literature, a measure is typically used that quantifies an individual's ability to differentially assess memory's failure and success (Benjamin \& Diaz, 2008). Because we assumed that the five points on the smiley scale were not equidistant in terms of subjective probability, especially in our young sample, we decided not to use a measure that converts CJs into probabilities (Dunlosky \& Meltcafe, 2009). Rather we subtracted the mean CJ for incorrect answers from the mean CJ for correct answers. Positive values indicate adequate metacognitive discrimination between correct and incorrect recall. In the literature, this measure has repeatedly been used, especially in young samples, to document emerging and improving metacognitive monitoring skills (for a recent overview see Roebers, in press).

\subsubsection{Theory of Mind}

ToM competencies were assessed at time 1 with two analogous tasks that tapped second-order ignorance (absence of knowledge, Hogrefe, Wimmer, \& Perner, 1986) and false belief adopted from previous studies (Sullivan, Zaitchik, \& Tager-Flusberg, 1994; Lockl \& Schneider, 2007; Lecce \& Hughes, 2010). The first task consisted of a story about a boy whose mother wanted to surprise him with a bunny for his birthday. While pictures were shown and the story was told to the participants, five control questions were asked to ensure that the children were following the story. The first test question assessed children's understandings of second-order ignorance, the second test question second-order false belief understanding, and with the third test question children were asked to justify their responses to the second test question, that is, show elaborated false belief understanding. The second task involved a story with two siblings, in which the brother deliberately misinformed his sister about the location of a chocolate bar, because he wanted it for himself. The control and the test questions for this second ToM task were paralleled to the first ToM task. We used the same scoring procedure as Lock and Schneider (2007) did and children received one point for a correct answer to one of the three test questions, provided that they had answered at least four of the five control question correctly. For the justifying answers of false belief understanding, the answers were coded as correct and incorrect based on a categorization by Sullivan et al. (1994). In order to obtain on general score for children's ToM performance in kindergarten we summed up the score from two the false belief tasks with an achievable maximum of 6 points.

At time 2 ToM competencies were assessed again with two tasks. One task was the same false belief story about the two siblings we already used at time 1. Because advanced ToM performance development continues into the school years, i.e. with the understanding of white lies, the second task included six strange stories, a set of vignettes or stories about everyday situations where people say things they do not mean literally (lie, white lie, pretended, misunderstanding, joke, appearance/reality, forget), translated from O'Hare et al. (2009), to assess if children were able to infer mental state concepts embedded in a naturalistic context. We used the same coding and scoring procedure as O'Hare et al. (2009) did: Children were always assigned a score for their best answer and could earn for each story one point for a correct partial mental state answer or two points for a full and accurate mental state answer. In order to obtain on general score for children's ToM competencies at the end of their first grade we summed up the score from the false belief task and the strange stories with an achievable maximum of 15 points.

\subsubsection{Language Ability}

Because children's language ability was assumed to be related with ToM as well as with metacognition (Sodian, Eisenbein, Kristen, \& Thoermer, 2010; Miller, 2006), children were also given a subtest of the Hannover-Wechsler-Intelligenztest für das Vorschulalter (HAWIVA®, Ricken, Schuck, \& Preuß, 2007). In each trial, children were shown four pictures and were asked to point to the one picture that best matched the meaning of a word or phrase (e.g., which picture shows parallel lines?). For every correct answer children received one point, with a maximum of 31 points.

\section{Results}

\subsection{Descriptive Analysis}

In the first step of our analyses, we examined all the variables of interest and correlated them with age at time 1 (see table 1). As expected correlations analysis revealed that nearly all variables were independent from age and therefore we did not control for age in the following data analysis. Next, we compared if children showed improved ToM competencies between time 1 and time 2. Because we used only one identical task (False Belief 
"Chocolate Story") at time 1 and time 2, we compared the performance on this task. A t-test revealed that there was no difference in ToM competencies between time 1 and time $2, t=-.60$, n.s.: children's second-order knowledge understanding did not improve during the study period. As to monitoring discrimination we first looked at children's recognition rate and then to their general ability to metacognitively discriminate between correct and incorrect recall in their CJ: children recognized on average $M=8.80, S D=3.40$ items at time 1 and $M=11.64, S D=3.00$ items at time 2 correctly (the increase in recognition rate was significant, $t=-8.43, p$ $<.001)$. As a result, we obtained sufficient CJ for both correct and incorrect recall. In analogue to previous studies (Roebers, 2002; Roebers et al., 2007), we compared the average CJ given after correct recall with the average CJ given after incorrect recall. Results from the analysis of variance (ANOVA) revealed that children gave significantly higher $\mathrm{CJ}$ for correctly recognized items than for incorrect items at time $1, F(1,110)=90.35$, $p<.001, \eta p^{2}=.37$ as well at time $2, F(1,110)=55.50, p<.001, \eta p^{2}=.34$. Looked at these data from a different perspective, the vast majority of the children $(81 \%$ at time 1 and $85 \%$ at time 2$)$ had a positive discrimination score. Thus, children proved to be well able to use the $\mathrm{CJ}$ scale and to metacognitively discriminate between correct and incorrect recall. Therefore, the discrimination score of the CJ (correct minus incorrect recall) can be used. When compared monitoring discrimination between time 1 and time 2, a t-test revealed no improved monitoring discrimination, $t=.01$, n.s. during the study period.

Table 1. Descriptive data of all variables of interest and correlation with age

\begin{tabular}{|c|c|c|c|}
\hline & $M(S D)$ & $\begin{array}{l}\text { Range } \\
\text { min. - max. }\end{array}$ & Correlation (r) with age \\
\hline \multicolumn{4}{|l|}{ Theory of Mind } \\
\hline T1 - False Belief "Chocolate Story" & $1.86(1.11)$ & $0-3$ & .11 \\
\hline T1 - False Belief "Birthday Story" & $1.93(1.07)$ & $0-3$ & .11 \\
\hline T1 - Theory of Mind Composite Score & $3.51(1.99)$ & $0-6$ & .09 \\
\hline T2 - False Belief "Chocolate Story" & $1.89(.94)$ & $0-3$ & .02 \\
\hline T2 - Strange Stories & $5.99(2.50)$ & $1-12$ & .09 \\
\hline T2 - Theory of Mind Composite Score & $7.73(2.90)$ & $1-14$ & .08 \\
\hline \multicolumn{4}{|l|}{ Monitoring } \\
\hline $\mathrm{T} 1$ - Mean CJ incorrect & $2.59(.93)$ & $.2-4$ & -.09 \\
\hline $\mathrm{T} 1$ - Mean CJ correct & $3.16(.73)$ & $1-4$ & .01 \\
\hline T1 - Monitoring Discrimination Score & $.58(.75)$ & $-1.5-2.5$ & .12 \\
\hline $\mathrm{T} 2$ - Mean CJ incorrect & $2.81(.95)$ & $0-4$ & -.16 \\
\hline $\mathrm{T} 2$ - Mean CJ correct & $3.38(.57)$ & $1.3-4$ & .08 \\
\hline $\mathrm{T} 2$ - Monitoring Discrimination Score & $.58(.81)$ & $-1-4$ & $.24 *$ \\
\hline \multicolumn{4}{|l|}{ Language } \\
\hline T1 - Language & $24.11(2.79)$ & $17-29$ & .01 \\
\hline
\end{tabular}

Note. ${ }^{*} p<.05$.

\subsection{Correlation Analysis}

In a second step and in reference to our main research question addressing the link between procedural monitoring abilities and ToM competencies, correlation analysis (see table 2) showed that early monitoring skills were related with later ToM competencies: children who showed a more accurate monitoring discrimination in 
kindergarten had a better second-order knowledge and advanced ToM understanding at the end of their $1^{\text {th }}$ grade. There was no relation in the other direction or at one time point itself. With respect to ToM competencies, correlations analysis showed that children with greater ToM competencies at time 1 also showed greater ToM competencies at time 2. As to monitoring discrimination, correlations analysis showed no relation in monitoring between the two measure points. When considering the relationship from language skills to both ToM and monitoring discrimination, correlation analysis revealed significant relationships to nearly all variables. Children with better language abilities in kindergarten tended do have a greater ToM competencies overall and showed more accurate monitoring discrimination, at least in kindergarten.

Thus, correlational analysis suggested that in transition from kindergarten to school children's ToM competencies are stable in development, whereas the ability to metacognitively discriminate fluctuated substantially. Furthermore, there is a relationship between early procedural metacognitive monitoring and later ToM competencies. Therefore, we next conducted multiple regressions analysis using standardized $\mathrm{z}$-values to find out if monitoring discrimination and ToM share a sustainable amount: because we were interested what are precursors for later monitoring discrimination abilities and ToM competencies, we conducted regression models including early monitoring discrimination, ToM competencies and language ability as predictor variables when aiming to predict later ToM and monitoring discrimination abilities.

Table 2. Bivariate pearson correlations among theory of mind, monitoring skills and language

\begin{tabular}{lllll}
\hline & 1. & 2. & 3. & 4. \\
\hline Time 1 & & & & \\
1. Theory of Mind & & & & \\
2. Monitoring Discrimination & .14 & & & \\
3. Language & $.47^{* *}$ & $.39^{* *}$ & & \\
Time 2 & & & & \\
4. Theory of Mind & $.34^{* *}$ & $.31^{* *}$ & $.46^{* *}$ & \\
5. Monitoring Discrimination & .09 & .08 & .12 & .09 \\
\hline
\end{tabular}
Note. ${ }^{* *} p<.001$.

\subsection{Regression Analysis}

The first regression analysis focused on predicting later ToM competencies. In a first step we entered only early ToM competencies as criterion variable in the model and results revealed a significant contribution to the prediction of later ToM competencies, $\beta=.34, R^{2}=.11, t=3.71, p<.001, F(1,109)=13.80, p<.001$. In a next step, we entered also early monitoring discrimination in the model and results showed that in addition to early ToM competencies, $\beta=.30, t=3.40, p<.05, F(2,108)=11.84, p<.001$, monitoring discrimination accounted for $9 \%$ of the variance, $\beta=.26, t=2.98, p<.05$. We finally entered also early language abilities in the model (see table 3 ) and results revealed that language abilities accounted additionally for $7 \%$ of the variance and there was no longer any effect for early ToM competencies and monitoring discrimination, $F(3,107)=11.94, p<.001$. Together, these results indicate that early ToM competencies, as well monitoring discrimination, can predict later ToM competencies, but this relationship seems due to shared variance with early language abilities which showed the strongest effect when predicting later ToM competencies.

The second regression analysis focused on predicting later monitoring discrimination abilities. In a first step, we entered only early monitoring discrimination abilities as criterion variable in the model and results revealed no contribution to the prediction of later monitoring discrimination, $F(1,109)=.77$, n.s. In a next step we entered additionally early ToM competencies in the model and results showed again no effect, $F(2,108)=.69$, n.s. We finally entered also early language abilities in the model (see table 3 ) and results revealed that language abilities had any effect neither on later monitoring skills, $F(3,107)=.64$, n.s. Together the results indicate that neither early monitoring discrimination, ToM competencies, nor early language abilities can predict later monitoring discrimination abilities. 
Table 3. The final regression analysis predicting later a) theory of mind and b) monitoring discrimination abilities as criterion variables and including early theory of mind, monitoring discrimination and language as predictor variables

a) Later Theory of Mind

b) Later Monitoring Discrimination

\begin{tabular}{lllll}
\hline & $\beta$ & $\mathrm{t}$ & $\beta$ & $\mathrm{t}$ \\
Early Theory of Mind & .16 & 1.72 & .04 & .36 \\
Early Monitoring Discrimination & .16 & 1.70 & .05 & .43 \\
Early Language & .32 & $3.18^{*}$ & .09 & .74 \\
\hline
\end{tabular}

Note. ${ }^{*} p<.05$.

\section{Discussion}

The major aim of the present study was to investigate a possible link between ToM competencies and procedural metacognitive monitoring abilities in children in the transition from kindergarten to school. While previous studies have addressed a possible relation between ToM and declarative metacognitive knowledge, this is one of the first studies including also a longitudinal perspective to look at procedural metacognitive skills.

Results revealed an association between children's metacognitive monitoring and ToM. However, this link held true for early monitoring skills and later ToM competencies only: children with better monitoring skills in kindergarten showed better ToM competencies at the end of the first grade (but not vice versa). But, the link was far from being perfect. Only a small amount of variance in later ToM competencies could be explained. Against the background of theoretical assumptions, that uncertainty monitoring may in fact take place on the perceptual (Carruthers, 2009), or on the implicit level, at least in non-human animals and in very young children (Flavell, 2003), the magnitude of the effect was small but in fact about as expected.

Admittedly, results do not argue strongly for the assumption that the ability to reflect on one's or others' mental states is a shared and substantial common ground. If that was the case, the link should be closer, and there should also be an association between early ToM competencies and later monitoring skills. Our results do neither unambiguously speak for two separate processes, one being purely perception-based (monitoring) and one being only meta-representational. Given that our monitoring task implied explicit and verbal reports, as did the ToM tasks, the association found may be due to commonalities on the superficial task-level. In the present study, one might argue that —on the surface level—monitoring skills and ToM competencies are related simply because they both were measured with language-based tasks. But, in our view there are more than surface-level-commonalties. This is because on the representational level, language can also be considered as the medium through which ongoing thinking processes are transmitted (Eksen \& Rackozcy, 2013), and this holds true for mental states of others as well as for certainty-uncertainty reports of oneself. When expressed in language, an evaluation of certainty of one's own performance (metacognitive monitoring) and describing mental states to others (ToM) clearly involves meta-representation. Therefore, as our results seem to suggest, language (and its symbolic or meta-representational abilities rather than simply verbal reporting) plays a crucial role in the relationship between metacognitive monitoring und ToM: both (early monitoring skills as well ToM competencies) were strongly correlated with language ability (see Table 2). Additionally early monitoring skills, ToM competencies and language ability seem to share a significant amount of the explained variance in later ToM competencies (see Table 3 ).

From the perspective of emerging symbolic skills in children, our findings possibly mirror a child's general ability to form, retrieve and use meta-representations. This may suggest qualitative differences in conceptual thinking in this age range. We are tempted to interpret these findings as showing that — as has been theoretically proposed (Kuhn, 2000; Wellmann, 1990) - these two domains of higher-order cognition share a common cognitive ground, beyond symbolic and/or language skills. We therefore propose that children's ability to form fully conscious meta-representations about others' and own mental states may underlie this link (Flavell, 2003); and this might be what we found in our results. In this line of argumentation, the present results may indicate a transition from an implicit to an additionally, more differentiated explicit metacognitive monitoring system at a certain age range (Balcomb \& Gerken, 2008), including fully conscious meta-representation. And in that view, monitoring skills must not necessarily rely on meta-representation but could also be based on feelings or 
experiences of uncertainty independent of conscious self-reflection (Diana \& Reder, 2004; Flavell, 2003) in this age range. Possibly, we did not find an association between early ToM competencies and later monitoring skills in our age range studied because children's later monitoring skills may still partly rely more on implicit sources and not solely on explicit meta-representation compared to their early ToM competencies. However, while Lockl and Schneider' findings (2007) suggested a relationship between early ToM and later declarative metacognition, we focused on procedural metacognition. We are tempted to argue that one reason for the somewhat disparate findings is that declarative metacognitive skills rely more strongly on meta-representations, and their nature is seemingly more concept-based than metacognitive monitoring. Another explanation for the diverging results might be that there is a developmental dissociation between procedural and declarative metacognition (Schneider, 2015): they follow different developmental trajectories and therefore show different relations to ToM at different time points in development.

Our results additionally raise the question if the role of early declarative metacognition has been underestimated so far and might be also developing even earlier from an implicit to a more differentiated explicit system at a certain age range. This interpretation is speculative at this point but indirectly supported by results suggesting that children at very young ages already have (at least implicit) access to internal knowledge states, providing an explanation for how they are able to guide learning (Balcomb \& Gerken, 2008; Lyons \& Ghetti, 2013). In that view, future research should address the question whether early (implicit) declarative metacognition skills can predict later ToM competencies as well.

Interestingly, it is not only for monitoring but also for ToM competencies that recent evidence suggests implicit skills early on. Through the development and use of innovative, behavioral rather than language-based ToM paradigms, it has been shown that even very young children (around the age of 18 months) possess an implicit false belief understanding (Buttelmann, Carpenter, \& Tomasello, 2009; Buttelmann, Over, Carpenter, \& Tomasello, 2014). Assuming that not only monitoring can occur without being fully self-reflective (see above), it may be argued that ToM competencies shown on the behavioral level also occur without being verbally expressed and fully conscious. In this line of argumentation, it would be interesting to explore the possibility that ToM and monitoring skills share a common ground (along with the ability to form explicit meta-representation) on such an implicit level. If perceptual-based monitoring tasks and behavioral ToM measures would be used in an individual differences approach including young children, this would provide insights into this theoretically relevant question.

Our results showed that children's performance in recognition rate is stable over time, because children with better performance in kindergarten performed also better at the end of their first grade. Furthermore and as it would be expected from well-established findings that memory improves during childhood and therefore performance getting greater (Schneider, 2015), there was also an increase in memory performance within a year of children's development. With regard to ToM, results revealed children with greater ToM competencies in kindergarten possessed greater ToM competencies on year later. In contrast, there seems to be no overall increase in ToM competencies within a year of children's development. This is somehow surprising because ToM competencies are assumed to develop into school years (O'Hare et al., 2009). One reason might be that a delay of one year is too short to document subtle developmental progress in that age range. Admittedly, we cannot rule out that this result is may be influenced by the fact that we used a new measure of advanced ToM understanding at the end of children's first grade, making firm conclusions about intra-individual development difficult. Concerning metacognitive monitoring our results showed that children are able to accurate monitor their performance and discriminate their certainty-uncertainty judgment at that age range. Interestingly, compared to ToM competencies, these monitoring skills were not stable over the testing period, because children with better monitoring skills in kindergarten did not show better monitoring skills at the end of their first grade. This leads to the interpretation that-in contrast to ToM competencies-monitoring skills at that age range still seem to be emergent abilities which are not yet sufficiently stabilized. And, because early language abilities could not explain later monitoring skills, a major and a theoretically important question remains open: what are potential precursors of monitoring skills? Future research is clearly needed.

Certainly, the magnitude of the assumed link between metacognition and ToM depends on the measures and tasks included. The fact that we used a memory-based rather than a perceptual-based monitoring measure may have facilitated the detection of a significant link as both our monitoring task and the ToM tasks required the formation, storage and retrieval of meta-representations. Another reason could be that awareness of metacognition could be associated with the ease of the task and that easier tasks are associated less with monitoring skills (Diana \& Reder, 2004). It would be informative to contrast in future research perceptually 
based and memory-based monitoring processes, both with respect to their developmental progression but also with respect to possible links to ToM competencies. Admittedly, our interpretations must be treated with cautious, as we did not include independent measures of cognitive abilities like performance per se. Moreover, as with other monitoring measure, e.g., gamma correlations, monitoring discrimination scores depend on recognition and therefore very high and very low performers dropped out of the analyses due to limited variance in correct/incorrect recognition and/or the corresponding metacognitive judgments. In contrast to gamma correlations, the monitoring discrimination score is independent of children's variance in certainty-uncertainty judgment and therefore a good measure for quantifying metacognitive monitoring in children.

\subsection{Conclusion}

To conclude, the present study provided some innovative and theoretically important empirical insights into possible common cognitive grounds of ToM and metacognition. Children's monitoring skills in kindergarten are related to their later ToM competencies at the end of their first grade, but language seems to play crucial role in that relationship. At the same time, challenging avenues for future research were uncovered: whether or not implicit and explicit forms of metacognition (procedural and declarative) and ToM co-exist and whether and how they interact with each other at any single point in ontogeny. Moreover, although the present study clearly confirms the important role of language in this domain of higher order cognitive development, the precise mechanisms underlying the relationship of metacognition and ToM and if one is the precursor of the other or if they are bidirectional related yet remain unclear.

\section{Acknowledgments}

We gratefully thank the participating children, their parents, school administrators, teachers and research staff who made this study possible.

\section{References}

Anthony, J. L., Williams, J. M., McDonald, R., \& Francis, D. J. (2007). Phonological processing and emergent literacy in younger and older preschool children. Annals of Dyslexia, 57, 133-137. http://dx.doi.org/10.1007/s11881-007-0008-8

Astington, J. W., \& Hughes, C. (2013). Theory of Mind: Self-Reflection and Social Understanding. In P. D. Zelazo (Ed.), The Oxford Handbook of Developmental Psychology (pp. 398-424). New York, NY: Oxford University Press. http://dx.doi.org/10.1093/oxfordhb/9780199958474.013.0016

Astington, J. W., \& Pelletier, J. (1996). The language of the mind: It's role in teaching and learning. In D. R. Olson, \& N. Torrance (Eds.), The handbook of education and human development: New models of learning, teaching, and schooling (pp. 593-619). Cambridge, MA: Blackwell. http://dx.doi.org/10.1111/ b. $9780631211860.1998 .00028 . x$

Balcomb, F. K., \& Gerken, L. (2008). Three-year-old children can access their own memory to guide responses on a visual matching task. Developmental Science, 11(5), 750-760. http://dx.doi.org/10.1111/ j.1467-7687.2008.00725.x

Benjamin, A. S., \& Diaz, M. (2008). Measurement of relative metamnemonic accuracy. In J. Dunlosky, \& R. A. Bjork (Eds.), Handbook of Metamemory and Memory (pp. 73-93). New York, NY: Psychology Press.

Beran, M. J., Smith, J. D., \& Perdue, B. M. (2013). Language-trained chimpanzees name what they have seen but look first at what they have not seen. Psychological Science, 24(5), 660-666. http://dx.doi.org/10.1177/0956797612458936

Blair, C., \& Diamond, A. (2008). Biological processes in prevention and intervention: Promotion of self-regulation and the prevention of early school failure. Development and Psychopathology, 20(3), 899-911. http://dx.doi.org/ 10.1017/S0954579408000436

Blair, C., \& Razza, R. P. (2007). Relating effortful control, executive function, and false belief understanding to emerging math and literacy ability in kindergarten. Child Development, 78(2), 647-663. http://dx.doi.org/10.1111/j.1467-8624.2007.01019.x

Buttelmann, D., Carpenter, M., \& Tomasello, M. (2009). Eighteen-month-old infants show false belief understanding in an active paradigm. Cognition, 112, 337-342. http://dx.doi.org/10.1016/ j.cognition.2009.05.006 
Buttelmann, D., Over, H., Carpenter, M., \& Tomasello, M. (2014). Eighteen-month-old understand false beliefs in an unexpected-contents task. Journal of Experimental Child Psychology, 119, 120-126. http://dx.doi.org/10.1016/j.jecp.2013.10.002

Call, J. (2010). Do apes know that they can be wrong? Animal Cognition, 13, 689-700. http://dx.doi.org/10.1007/s10071-010-0317-x

Caputi, M., Lecce, S., Pagnin, A., \& Banerjee, R. (2012). Longitudinal Effects of Theory of Mind on Later Peer Relations: The Role of Prosocial Behavior. Developmental Psychology, 48(1), 257-270. http://dx.doi.org/10.1037/a0025402

Carruthers, P. (2009). How we know our own minds: The relationship between mindreading and metacognition. Behavioral and Brain Sciences, 32, 121-182. http://dx.doi.org/10.1017/S0140525X09000545

Davis-Unger, A. C., \& Carlson, S. M. (2008). Children's Teaching Skills: The Role of Theory of Mind and Executive Function. Mind, Brain and Education, 2(3), 128-135. http://dx.doi.org/10.1111/ j.1751-228X.2008.00043.x

Diana, R., \& Reder, L. M. (2004). Visual and verbal metacognition: Are they really different. In D. T. Levin (Ed.), Thinking and seeing, Visual metacognition in adults and children (pp. 187-201). Cambridge, MA: MIT Press.

Duncan, G. J. et. al. (2007). School Readiness and Later Achievement. Developmental Psychology, 43(6), 1428-1446. http://dx.doi.org/10.1037/0012-1649.43.6.1428

Dunlosky, J., \& Meltcafe, J. (2009). Metacognition. Thousand Oaks, CA: SAGE Publications, Inc.

Efklides, A. (2008). Metacognition. Defining its facets and levels of functioning in relation to self-regulation and co-regulation. European Psychologist, 13(4), 277-287. http://dx.doi.org/ 10.1027/1016-9040.13.4.277

Esken, F., \& Rakoczy, H. (2013). Metakognition und Mindreading. In A. Stephan, \& S. Walter (Eds.), Handbuch Kognitionswissenschaft (pp. 444-452). Stuttgart/Weimar: Metzler.

Flavell, J. H. (2003). Varieties of uncertainty monitoring. Behavioral and Brain Sciences, 26(3), 344. http://dx.doi.org/10.1017/S0140525X03270084

Happé, F. (2003). Theory of Mind and the Self. Annals of the New York Academy of Sciences, 1001, 134-144. http://dx.doi.org/10.1196/annals.1279.008

Heine, A., Engl, V., Thaler, V. M., Fussenegger, B., \& Jacobs, A. M. (2012). Neuropsychologie von Entwicklungsstörungen schulischer Fertigkeiten. Göttingen: Hogrefe.

Hogrefe, G. J., Wimmer, H., \& Perner, J. (1986). Ignorance versus False Belief: A Developmental Lag in Attribution of Epistemic States. Child Development, 57(3), 567-582. http://dx.doi.org/10.2307/1130337

Jäger, R. (2004). Konstruktion einer Ratingskala mit Smilies als symbolische Marken. Diagnostica, 50(1), 31-38. http://dx.doi.org/10.1026/0012-1924.50.1.31

Jenkins, J. M., \& Astington, J. W. (2000). Theory of Mind and Social Behavior: Causal Models Tested in a Longitudinal Study. Merrill-Palmer Quarterly, 46(2), 203-220.

Kleitman, S., \& Moscrop, T. (2010). Self-Confidence and Academic Achievements in Primary-School Children: Their Relationships and Links to Parental Bonds, Intelligence, Age, and Gender. In A. Efklides, \& P. Misailidi (Eds.), Trends and Prospects in Metacognition Research (pp. 293-327). New York, NY: Springer. http://dx.doi.org/10.1007/978-1-4419-6546-2_14

Kuhn, D. (2000). Theory of mind, metacognition, and reasoning: A life-span perspective. In P. Mitchell, \& K. J. Riggs (Eds.), Children's reasoning and the mind (pp. 301-326). East Sussex: Psychology Press Ltd.

Lecce, S., \& Hughes, C. (2010). The Italian job?: Comparing theory of mind performance in British and Italian children. British Journal of Developmental Psychology, 28, 747-766. http://dx.doi.org/10.1348/ 26151009X479006

Lecce, S., Caputi, M., \& Pagnin, A. (2014). False-belief understanding at age 5 predicts beliefs about learning in year 3 of primary school. European Journal of Developmental Psychology. http://dx.doi.org/10.1080/ 7405629.2014 .949665 
Lockl, K., \& Schneider, W. (2003). Metakognitive Überwachungs-und Selbstkontrollprozesse bei der Lernzeiteinteilung von Kindern. Zeitschrift für Pädagogische Psychologie, 17(3-4), 173-183. $\mathrm{http}: / / \mathrm{dx}$.doi.org/10.1024//1010-0652.17.3.173

Lockl, K., \& Schneider, W. (2007). Knowledge about the Mind: Links between Theory of Mind and Later Metamemory. Child Development, 78(1), 148-167.

Lyon, T. D., \& Flavell, J. H. (1994). Young children's understanding of "remember" and "forget". Child Development, 62, 1357-1371.

Lyons, K. E., \& Ghetti, S. (2010). Metacognitive development in early childhood: New questions about old assumptions. In A. Efklides, \& P. Misialida (Eds.), Trends and prospects in metacognition research (pp. 259-278). New York, NY: Springer. http://dx.doi.org/10.1007/978-1-4419-6546-2_12

Lyons, K. E., \& Ghetti, S. (2011). The development of uncertainty monitoring in early childhood. Child Development, 82(6), 1778-1787. http://dx.doi.org/10.1111/j.1467-8624.2011.01649.x

Lyons, K. E., \& Ghetti, S. (2013). I don't want to pick! Introspection on uncertainty supports early strategic behavior. Child Development, 82, 1178-1187. http://dx.doi.org/10.1111/cdev.12004

Miller, C. A. (2006). Development Relationships between Language and Theory of Mind. American Journal of Speech-Language Pathology, 15, 142-154.

Misailidi, P. (2010). Children's metacognition and theory of mind: Bridging the gap. In A. Efklides, \& P. Misailidi (Eds.), Trends and Prospects in Metacognition Research (pp. 279-291). Springer. http://dx.doi.org/ 10.1007/978-1-4419-6546-2_13

Nelson, T. O., \& Narens, L. (1990). Metamemory: A theoretical framework and new findings. In G. Bower (Ed.), The psychology of learning and motivation: Advances in research and theory (pp. 125-173). New York, NY: Academic Press. http://dx.doi.org/10.1016/S0079-7421(08)60053-5

O’Hare, A. E., Bremner, L., Nash, M., Happé, F., \& Pettigrew, L. M. (2009). A clinical Assessment Tool for Advanced Theory of Mind Performance in 5 to 12 Year Olds. Journal of Autism and Developmental Disorders, 39, 916-928. http://dx.doi.org/10.1007/s10803-009-0699-2

Pressley, M., Levin, J. R., Ghatala, E. S., \& Ahmad, M. (1987). Test Monitoring in Young Grade School Children. Journal of experimental child psychology, 43, 96-111. http://dx.doi.org/10.1016/ 0022-0965(87)90053-1

Ricken, G., Fritz, A., Schuck, K., \& Preuss, U. (Eds). (2007). HAWIVA-III. Hannover-Wechsler-Intelligenztest für das Vorschulalter-III. Übersetzung und Adaption der "WPPSI-III"von Wechsler D. Göttingen: Verlag Hans Huber, Hogrefe AG.

Roderer, T., \& Roebers, C. M. (2010). Explicit and implicit confidence judgments and developmental differences in metamemory: An eye-tracking approach. Metacognition Learning, 5, 229-250. http://dx.doi.org/10.1007/s11409-010-9059-z

Roderer, T., \& Roebers, C. M. (2014). Can you see me thinking (about my answers)? Using eye-tracking to illuminate developmental differences in monitoring and control skills and their relation to performance. Metacognition and Learning, 9(1), 1-23. http://dx.doi.org/10.1007/s11409-013-9109-4

Roebers, C. M., Krebs, S. S., \& Roderer, T. (2014). Metacognitive monitoring and control in elementary school children: Their interrelations and their role for test performance. Learning and Individual Difference, 29, 141-149. http://dx.doi.org/10.1016/j.lindif.2012.12.003

Roebers, C. M. (2002). Confidence Judgements in Children's and Adults' Event Recall and Suggestibility. Developmental Psychology, 38(6), 1052-1067. http://dx.doi.org/10.1037//0012-1649.38.6.1052

Roebers, C. M. (in press). Children's deliberate memory development: The contribution of strategies and metacognitive processes. In P. Bauer, \& R. Fivush (Eds.), The Blackwell Handbook of Memory Development. http://dx.doi.org/10.1002/9781118597705.ch37

Roebers, C. M., \& Howie, P. (2003). Confidence judgments in event recall: Developmental progression in the impact of question format. Journal of Experimental Child Psychology, 85, 352-371. http://dx.doi.org/10.1016/S0022-0965(03)00076-6 
Roebers, C. M., von der Linden, N., Schneider, W., \& Howie, P. (2007). Children's metamemorial judgments in an event recall task. Journal of Experimental Child Psychology, 97, 117-137. http://dx.doi.org/10.1016/ j.jecp.2006.12.006

Schneider, W. (2010). Metacognition and Memory Development in Childhood and Adolescence. In H. S. Waters, \& W. Schneider (Eds.), Metacognition, Strategy Use, and Instruction (pp. 55-81). New York, NY: Guilford Press.

Schneider, W. (2015). Memory of Development from Early Childhood Trough Emerging Adulthood. Cham, Heidelberg, New York, Dordrecht, London: Springer. http://dx.doi.org/10.1007/978-3-319-09611-7

Schneider, W., \& Lockl, K. (2008). Procedural Metacognition in Children: Evidence for Developmental Trends. In J. Dunlosky, \& R. A. Bjork (Eds.), A Handbook of memory and metamemory (pp. 391-409). Mahawa, NJ: Erlbaum.

Sodian, B., Eisenbein, H., Kristen, S., \& Thoermer, C. (2010). Gedächtnis, Metagedächtnis und Theory of Mind. In H. P. Trolldenier, W. Lenhard, \& P. Marx (Eds.), Brennpunkte der Gedächtnisforschung (pp. 107-128). Göttingen: Hogrefe.

Sodian, B., Prest, H., \& Meinhardt, J. (2012). Entwicklung der Theory of Mind in der Kindheit. In H. Förstl (Ed.), Theory of Mind (pp. 61-77). Berlin: Springer-Verlag. http://dx.doi.org/10.1007/978-3-540-27241-0_5

Sullivan, K., Zaitchik, D., \& Tager-Flusberg, H. (1994). Preeschoolers can attribute second-order beliefs. Developmental Psychology, 30(2), 395-402. http://dx.doi.org/10.1037//0012-1649.30.3.395

Washburn, D. A., Gulledge, J. P., Beran, J., \& Smith, J. D. (2010). With his memory magnetically erased, a monkey knows he is uncertain. Biology Letters, 6, 160-162. http://dx.doi.org/10.1098/rsbl.2009.0737

Wellman, H. M. (1990). The Child's Theory of Mind. Cambridge, MA: MIT Press.

Wellman, H. M., Cross, D., \& Watson, J. (2001). Meta-Analysis of Theory of Mind Development: The Truth about False Belief. Child Development, 72(3), 655-684. http://dx.doi.org/10.1111/1467-8624.00304

Wimmer, H., \& Perner, J. (1983). Beliefs about beliefs: Representation and constraining function of wrong beliefs in young children's understanding of deception. Cognition, 13, 103-128. http://dx.doi.org/10.1016/ 0010-0277(83)90004-5

\section{Copyrights}

Copyright for this article is retained by the author(s), with first publication rights granted to the journal.

This is an open-access article distributed under the terms and conditions of the Creative Commons Attribution license (http://creativecommons.org/licenses/by/3.0/). 